\title{
A FERRAMENTA CHAT COMO RECURSO PEDAGÓGICO NO ENSINO DE FÍSICA
}

José Ailton Forte Feitosa | ailtonforte@gmail.com

Mestrado em Ciências e Matemática pela Universidade Federal do Ceará (UFC).Professor da Pós-Graduação em Educação Matemática da Universidade Estadual Vale do Acaraú (UVA) e coordenador do curso de Matemática semipresencial do programa UAB/UFC. Pesquisador na área de tecnologias digitais para educação, informática educativa e educação a distância.

Ivoneide Pinheiro de Lima | ivoneidepinheirodelima@gmail.com

Professora da Pós-Graduação em Educação e coordenadora do subprojeto de Matemática do PIBID da Universidade Estadual do Ceará (UECE). Professora de Matemática do Centro de Educação, Ciência e Tecnologia da Região de Inhamuns (CECITEC).

Francisco Lima Herbert Vasconcelos | herbert@virtual.ufc.br

Doutorando em Engenharia de Teleinformática. Professor da Universidade Federal do Ceará (UFC). Consultor da Secretaria de Educação Básica do Ministério da Educação (MEC). Pesquisa em computação aplicada, tecnologias digitais para a educação, informática educativa, educação a distância e recursos tecnológicos para o ensino on-line. Membro da Electricaland Electronics Engineers, Inc. (IEEE).

\section{Resumo}

O presente estudo investigou as interações ocorridas em duas disciplinas (Física Introdutória I e II) ministradas na modalidade semipresencial, ligadas ao programa Universidade Aberta do Brasil (UAB). A metodologia utilizada consistiu, no primeiro momento, em analisar dois registros de sessões de chat com o intuito de identificar padrões de recorrência comuns; outra parte da metodologia consistiu em aplicar um questionário com oito questões a 135 alunos matriculados nas referidas disciplinas em doze polos do curso de Licenciatura em Química, ofertado pela parceria Universidade Federal do Ceará (UFC)/UAB. A pesquisa teve como finalidade investigar a concepção desses alunos a respeito da utilização do chat no esclarecimento de dúvidas de listas de exercícios de Física. O ambiente de aprendizagem a distância utilizado foi o Solar. Os resultados apontam que, apesar das limitações da ferramenta chat, a sua utilização foi importante para o esclarecimento das dúvidas e o aumento da interação entre professor/tutor-aluno e entre os alunos.

\section{Palavras-chave}

Ensino de física. chat. Interação. 


\section{The chat tool as an educational resource in the Teaching of Physics}

\section{Abstract}

The present study investigated the interactions occurring in two disciplines (Introductory Physics I and II), taught in blended mode, associated with the program Open University of Brazil (UAB). The methodology used consisted of first time to examine two records of chat sessions, in the aim to identify common patterns of recurrence; another part of the methodology consisted of applying a questionnaire with eight questions to 135 students enrolled in those courses in twelve poles of the course degree in Chemistry offered by the partnership UFC/UAB. The research aims to investigate the design of these students about the use of chat through the virtual platform Solar, answering questions in the list of exercises in Physics. The distance learning environment was used Solar. The results show that despite the limitations of chat tool, its use was important to clarify the doubts and increasing interaction between teacher/tutor-student and student-learners.

\section{Keywords}

Teaching of Physics. chat. Interaction.

\section{Introdução}

Nos últimos tempos, percebemos no Brasil uma série de profundas e rápidas transformações ocorrendo em todos os setores, tanto de ordem política, como econômica e social, de modo que, no meio educacional, diferentes exigências estão sendo feitas na perspectiva de acompanhar o dinamismo $e$ a rápida evolução tecnológica que atinge o mundo e que satisfaçam as demandas profissionais e pessoais, sem esquecer a qualidade do processo de ensino e aprendizagem.

A Educação a Distância $(\mathrm{EaD})$ via internet vem ao encontro dessas exigências, que são imprescindí- veis à sociedade moderna, no sentido de aumentar a oferta de vagas nos cursos e contribuir para o desenvolvimento da educação científica. $\mathrm{A} \mathrm{EaD}$ tem grande contribuição para a formação de indivíduos, especificamente no atendimento à população adulta, que, por motivos pessoais, geográficos e/ou profissionais não pôde dar continuidade ou completar seus estudos no modelo convencional, mas que precisa de educação de qualidade com atualização tecnológica e que se ajuste às necessidades individuais somadas às requisições do mercado de trabalho.

Considerando que a comunicação é imprescindível para o desenvolvimento de qualquer curso em $\mathrm{EaD}$, a ferramenta chat é um dos meios disponíveis que possibilitam o diálogo em tempo real (síncrono) entre os participantes do curso. Nessa expectativa, apresentaremos neste trabalho uma experiência com o uso dessa ferramenta nas disciplinas de Física Introdutória I e II do curso de Licenciatura em Química da Universidade Federal do Ceará (UFC), ligados ao Programa da Universidade Aberta do Brasil (UAB). Participaram deste estudo 135 alunos pertencentes a doze municípios cearenses: Aracati, Aracoiaba, Barbalha, Brejo Santo, Camocim, Campos Sales, Caucaia, Jaguaribe, Russas, São Gonçalo do Amarante, Quiteranópolis, Quixeramobim.

O estudo teve como objetivo investigar a concepção desses alunos a respeito da utilização do chat no esclarecimento de dúvidas oriundas das listas de exercícios de Física. O ambiente de aprendizagem a distância utilizado foi o Solar (www.solar.virtual.ufc.br).

Esse ambiente foi pensado a partir da concepção sociointeracionista de Vygotsky. Foi elaborado e implantado pela equipe de professores e pesquisadores do Instituto UFC Virtual. Ele consiste de um espaço de discussão, reflexão e publicação de registros, favorecendo uma aprendizagem colaborativa. Possui diferentes recursos, como agenda, fóruns, portfólios, chat e videoconferência, entre outros.

Os instrumentos de pesquisa usados foram: 24 registros de sessões de chat e um questionário. Cada sessão de chat teve em média a duração de uma hora; 
eram disponibilizados três horários distintos para que os alunos pudessem escolher o melhor momento para participar. Em geral, em dias díspares, era oferecido um horário no período da manhã, outra a tarde e outro à noite.

Para preservar a identidade dos alunos e dos professores/tutores, usaremos pseudônimos nos trechos retirados dos chats. Denominaremos de professor/tutor o responsável por conduzir, mediar às interações. Os trechos serão apresentados na íntegra, inclusive com os desvios ortográficos e gramaticais.

O questionário foi aplicado no último encontro presencial de cada disciplina investigada, assegurando ao aluno a preservação de sua identidade. Esse instrumento abordou os aspectos pedagógicos, a interatividade, as possibilidades e as limitações do chat; o objetivo central era conhecer a aceitação dos alunos a respeito dessa ferramenta no contexto do ensino de Física. A efetivação dessa etapa foi em torno de 30 minutos.

\section{O chat como recurso pedagógico}

Nos últimos tempos, observamos grande crescimento das tecnologias, especialmente após a disseminação da internet (LINS; MOITA; DACOL, 2006), o que possibilitou a criação de novos meios para o processo de aprendizagem, como é o caso da ferramenta chat usada em diferentes ambientes virtuais de aprendizagem (AVAs), como Moodle, TelEduc, Blackboard e Solar. Mas, afinal, o que caracteriza a ferramenta chat? Quais as suas potencialidades na educação em $\mathrm{EaD}$ ?

A princípio, o chat foi concebido apenas como uma forma de entretenimento entre estudantes, para descontraí-los e relaxá-los fazendo uso de bate-papos escritos. Segundo Pereira (2004), essa ferramenta surgiu em 1988 na Finlândia e era conhecido como Internet Relay Chat (IRC). Foi imaginado, organizado e implantado por Jarkko Oikarinem, quando realizou a primeira experiência de comunicação em tempo real por meio da internet.

O sucesso desse recurso foi tanto entre os alunos que sua expansão e repercussão se desenvolve- ram rapidamente. Posteriormente, o chat revelou-se uma ferramenta importante para o ensino em $\mathrm{EaD}$, especialmente por possibilitar o diálogo simultâneo entre os participantes do curso, incentivando "cada vez mais a participação do aluno no curso de EaD" (LEAL, 2007, p. 58). Além de admitir a possibilidade de esclarecer dúvidas e aprofundar, de forma imediata, a temática em foco.

O chat se caracteriza como um ambiente destinado à aprendizagem no qual há ausência de conteúdo expositivo, permitindo a discussão e a reflexão de temas direcionados e de interesse do grupo, propiciando ao aluno uma melhor percepção do outro e ajudando-o a aperfeiçoar, ampliar e/ou desenvolver outra concepção sobre o objeto em estudo, pois permite aos alunos consultar os professores/tutores online, minimizando suas dúvidas. Por meio do chat, os participantes do curso dialogam entre si de forma síncrona, no debate de uma temática para o crescimento intelectual de todo o grupo (GEROSA et al, 2003).

O chat é um recurso pedagógico importante para $\mathrm{EaD}$, por favorecer o desenvolvimento de atividade referenciada no diálogo, objetivando a "incorporação da ideia do outro às próprias ideias, a reconstrução de conceitos e a reelaboração das representações expressas pela escrita" (ALMEIDA, 2006, p. 210), além de possibilitar ao professor-tutor um diagnóstico imediato da captação ou dificuldade do aluno face aos conceitos abordados, permitindo mediações em curto prazo de tempo. Esse fato sinaliza momentos positivos, tanto no aspecto da aprendizagem como em relação à comunicação do professor/tutor-alunos e dos alunos entre si.

Fazendo uma analogia com a sala de aula convencional, podemos dizer que a discussão provocada pelo uso do chat muito se assemelha àquelas feitas no ensino presencial, em que os alunos podem interrogar e explanar suas dúvidas ao mesmo tempo que elas surgem. A esse respeito, Junqueira comenta que "o chat permite trocas entre alunos e professores que parecem suprir, de forma mais satisfatória, a carência dos alunos por espaços e práticas que remetam às tradições da sala de aula presencial" (2010, p. 2). 
Assim, o emprego do chat beneficia a socialização e a construção do conhecimento, fortalecendo a relação entre os participantes. Para o sucesso do chat, sob a perspectiva pedagógica, é preciso que ele seja pensado antes, durante e depois.

$\mathrm{O}$ antes indica que ele tem de ser organizado (planejado) pelo professor/tutor abordando os seguintes aspectos: tema de discussão, objetivos, horários de acesso, inclusão de perguntas que nortearão a conversa on-line, dentre outros.

$\mathrm{O}$ durante significa que a mediação feita pelo professor/tutor deve ser adequada e condizente com o objeto em foco, tentando evitar as conversas paralelas e sem qualquer relação com a temática, em que cada um manifesta sua opinião e não se sabe quem responde a quem. É o momento em que o aluno e o professor/tutor fazem leituras rápidas das mensagens recebidas, filtrando aquelas que são pertinentes, pois muitas mensagens chegam ao mesmo tempo. Favorece também o feedback instantâneo do julgamento do aluno, possibilitando-lhe refazer e se posicionar novamente, enriquecendo assim a discussão.

Admite também a possibilidade de esclarecimento de dúvidas, questionamentos e posicionamentos de forma articulada com os pensamentos dos colegas e do professor/tutor. Um fator importante é que "o professor/tutor não procure responder perguntas individuais dos alunos, mas, sim, que concentre a atuação em pontos comuns propostos por ele no planejamento prévio ou pelos alunos ao longo do chat" (Idem, 2010, p. 4).

O depois consiste no momento após a realização do chat, em que o professor/tutor deverá refletir sobre a atividade realizada, a fim de confrontar se os objetivos foram alcançados para a correção de eventuais problemas no planejamento previsto. A ideia central é reorganizar esse planejamento para não repetir os equívocos em outro chat. É importante ainda disponibilizar uma cópia do chat para que os alunos possam rever e/ou estudar os principais tópicos abordados. Nesse sentido, Martins; Oliveira e Cassol comentam que é produtivo utilizar o chat também após a sua realização. O registro da conversa on-line pode ser tratado como um texto "desorganizado" a ser trabalhado tanto pelo professor como pelos alunos, categorizando as questões emergentes para serem discutidas em outra ferramenta do ambiente, por exemplo o fórum de discussão (MARTINS; OLIVEIRA; CASSOL, 2005, p. 5).

Todo esse processo de construção e reconstrução do planejamento do chat demanda do professor/ tutor flexibilidade, tempo e responsabilidade para aprimorar as questões decorrentes e inusitadas no sentido de atender aos propósitos do curso.

\section{Caracterizações das disciplinas Física In- trodutória I e II}

A disciplina Física Introdutória I foi dada no primeiro semestre do curso de Química, com carga-horária de $64 \mathrm{~h} / \mathrm{a}$, totalizando quatro créditos. Para a realização da disciplina, houve dois encontros presenciais, com carga horária de 16h/a, nos dias 04/08 e 01/09 de 2010. O estudo a distância foi realizado nos meses de agosto e setembro de 2010. Ao longo da disciplina foram realizadas duas sessões de chat, cujo foco central era a resolução de listas de exercícios, destinadas a todos os alunos matriculados na disciplina.

A disciplina Física Introdutória II foi ofertada no segundo semestre do curso, com carga horária de 64 h/a, totalizando quatro créditos. Para o desenvolvimento da disciplina, ocorreram dois encontros presenciais, com carga horária de $8 \mathrm{~h} / \mathrm{a}$ cada um, nos dias 06/05 e 03/06 de 2009. O momento a distância ocorreu nos meses de maio e junho de 2009. Durante o curso, aconteceram também duas sessões de chat, agendadas previamente para a discussão dos temas da disciplina e para o esclarecimento de dúvidas dos alunos na lista de exercícios.

É importante registrar que os alunos de Física Introdutória I não foram os mesmos da Física Introdutória II. 


\section{Análises das sessões de chat}

Ao analisar o corpus, que consistiu nos trechos do chat, percebemos que existiam momentos de interações que eram comuns (codificação) a todas as sessões. Para classificá-las, utilizamos a análise de conteúdo explicitado por Bardin (2008), que representa um conjunto de técnicas (categorização) adotadas para análises dos diálogos, visando obter pontos repetitivos (codificação), a fim de inferir um procedimento que ajude a compreender o fenômeno investigado.
Isso significa ir além da simples leitura do discurso, mas "compreender criticamente o sentido das comunicações, seu conteúdo manifesto ou latente, as significações explícitas ou ocultas" (CHIZZOTTI, 2006, p. 98). Os registros foram então classificados e categorizados em sete momentos: ambientação, notas de provas, listas de exercícios, problemas de conexão, outros, desenvolvimento e conclusão. O Quadro 1 apresenta a descrição de cada momento utilizado na análise das comunicações escritas on-line.

Quadro 1: Descrição de cada momento do chat

\begin{tabular}{|c|c|}
\hline Momento & Finalidade \\
\hline Ambientação & Dar as boas-vindas aos alunos. \\
\hline Notas de provas & Os alunos indagavam sobre as notas das avaliações individuais já realizadas. \\
\hline Listas de exercícios & O momento em que o professor/tutor destaca para os alunos o objetivo do chat. \\
\hline Problemas de conexão & Dificuldades relacionadas a conectividade e estabilidade durante a realização do chat. \\
\hline Outros & $\begin{array}{l}\text { Mensagens dos alunos relacionadas a problemas diversos, tais como: falta de apostila, } \\
\text { falta de professor/tutor presencial, declarações, matrículas e outros. }\end{array}$ \\
\hline Desenvolvimento & $\begin{array}{l}\text { Foi o momento em que as intensidades de interações foram acentuadas; nesse período } \\
\text { aconteceram as resoluções das questões envolvendo os conceitos abordados nas aulas } \\
\text { por parte do professor/tutor e as colaborações dos alunos. }\end{array}$ \\
\hline Conclusão & $\begin{array}{l}\text { Fase final das interações, ocorrendo as despedidas entre os interlocutores e os agrade- } \\
\text { cimentos. }\end{array}$ \\
\hline
\end{tabular}

Fonte: Pesquisa direta.

Esses dados nos mostram que todos os professores/tutores seguiram, de certo modo, o mesmo padrão para o desenvolvimento do chat abordando esses sete momentos. Porém cada qual no seu ritmo e de acordo com a dinâmica da turma. Os gráficos 1 e 2 exemplificam os sete momentos em uma das sessões de chat realizadas nos polos de Barbalha e Aracati, respectivamente. Os polos foram escolhidos aleatoriamente. 
Gráfico 1: Momentos de interações do polo de Barbalha

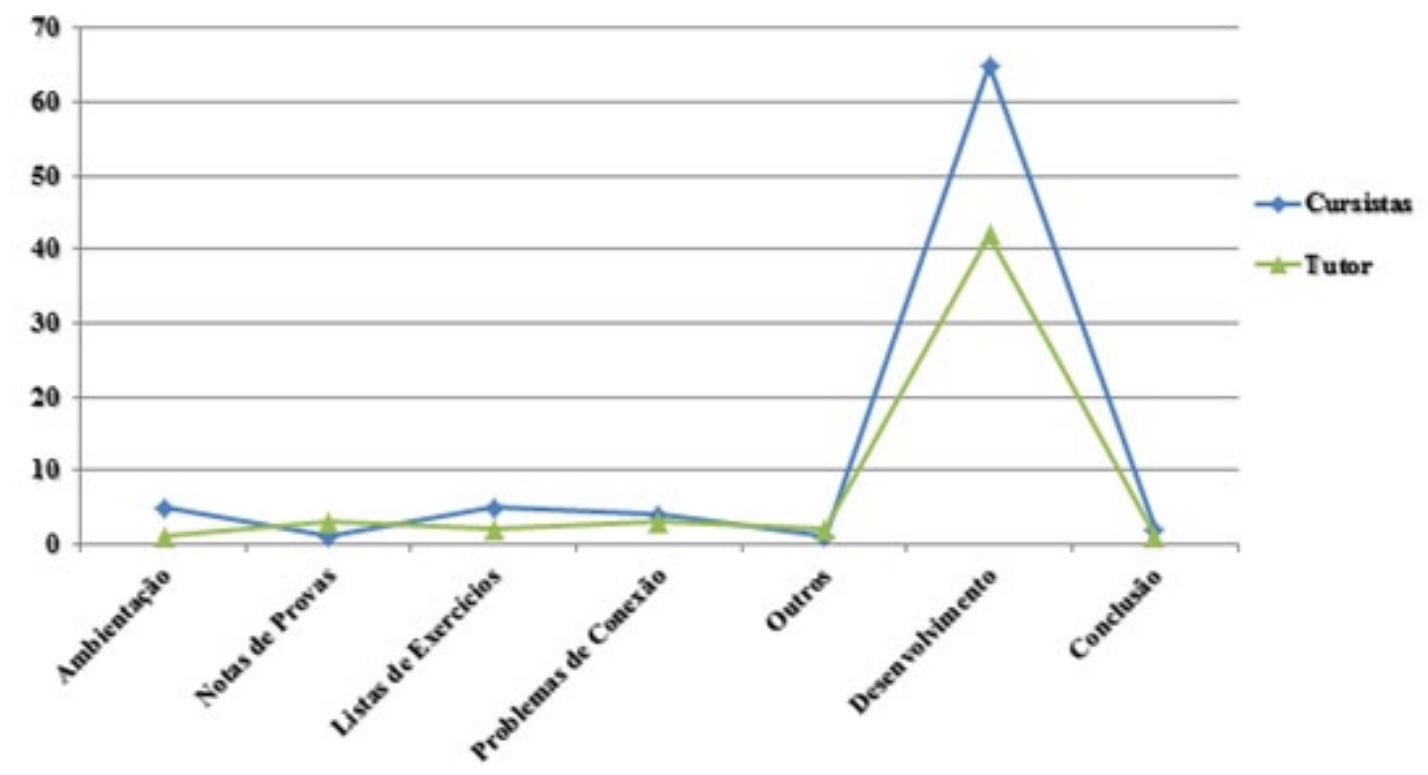

Fonte: Pesquisa direta

Gráfico 2: Momentos de interação do polo de Aracati

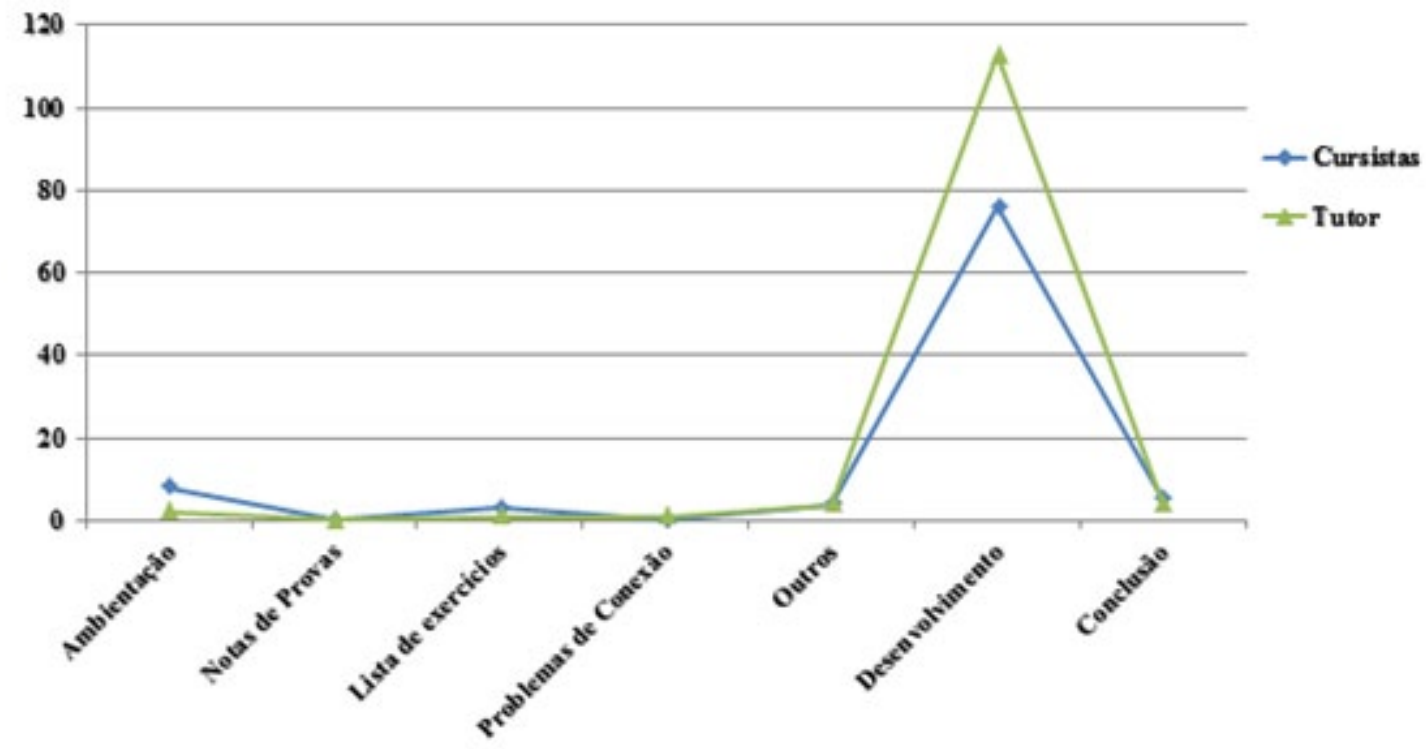

Fonte: Pesquisa direta

Com base nos gráficos, é possível destacar o momento em que ocorreu o pico das interações entre professor/tutor e alunos. Percebermos que houve maior intensidade de mensagens enviadas entre os agentes envolvidos no chat durante o momento caracterizado como desenvolvimento. Esse fato foi decorrente das discussões geradas em torno da resolução da lista de exercícios. Isso exprime que foi o momento em que as dúvidas dos alunos vieram à tona e o professor/tutor buscava esclarecê-las. De modo semelhante, essa situação ocorreu também nos outros polos analisados. 
Outro ponto que merece destaque é que, no polo de Aracati, as interações ocorridas foram quase o dobro do que ocorreu em Barbalha. Esse aspecto nos leva a interpretar que houve maior empenho por parte do professor/tutor no sentido de provocar a participação da turma, envolvendo-a nos debates e atividades propostas, tornando assim o diálogo ativo.

Ressaltamos, com referência em Maia e Mattar (2007), que o professor/tutor tem papel essencial na in- termediação da ação do aluno, pois a comunicação bi e multidirecional contribuem para que a turma se torne mais confiante, manifestando suas opiniões e discutindo determinados assuntos, favorecendo assim, maior autonomia no aluno. A seguir apresentamos um fragmento de mensagem que foi retirado de uma das sessões de chat para ilustrar o momento desenvolvimento:

\section{Professor/tutor pergunta para Carla:}

Todos poderão entregar as listas 1 e 2 até $2^{a}$ feira (25/05/2009) na área pública. Leiam seus e-mails esse final de semana que deverei está mandando dicas de como resolver as listas 1 e 2.

\section{João fala para TODOS:}

Professor, com relação à questão 01 acha que não tive dúvidas, mas gostaria de que fossem feitos alguns comentários, pois só fiz referência aos itens II e III.

\section{Carla fala para Professor/tutor:}

ainda bem, pq eu só consegui postar o protifolio 2

\section{Professor/tutor pergunta para João:}

Você afirmou que o item II e III estão errados, certo?

\section{Professor/tutor pergunta para João:}

No item II está claro, pois sabemos que um corpo neutro tem prótons e elétrons na mesma quantidade

\section{Professor/tutor pergunta para João:}

O que responde também ao item III.

\section{JUAREZ SILVA fala para TODOS:}

Para o item II justifiquei que para um corpo está eletrizado é necessário que o número de cargas elétricas seja diferente.

Fonte: Sessão de chat de Física Introdutória II, realizado no Polo de Camocim dia 22 de maio de 2009.

O texto mostra que o professor/tutor buscou manter o foco das discussões, envolvendo os alunos no debate, evitando uma possível fuga do tema (DAVID, 2010). Essa atitude do professor/tutor foi fundamental na perspectiva da aprendizagem, pois os participantes se engajaram no debate em torno da resolução da lista de exercícios, contribuindo assim para que as interações ocorressem de forma colaborativa. Pratt e Palloff (2004) expõem que o aluno, ao sentir que o professor/tutor está "presente" no curso, sente-se mais seguro para participar das discussões e realizar as atividades solicitadas, haja vista que é o professor/tutor que promove a intermediação no chat. 


\section{Análise do questionário: concepção dos alunos a respeito do chat}

Apresentaremos apenas as análises de três das oito questões que foram utilizadas na pesquisa, considerando a adequação da finalidade deste trabalho. Cada questão foi sistematizada e organizada por dois gráficos. O primeiro é referente ao percentual total relativo a todos os polos investigados; o segundo gráfico apresenta a situação de cada polo. O objetivo dessa metodologia foi ter uma visão geral e individual das respostas de cada questão do questionário; a margem significativa considerada nesta pesquisa foi o percentual maior que $50 \%$.

\section{Questão 1: Opinião sobre o chat no ensino de Física}

Os dados do gráfico 3 divulgam que $3 \%$ dos entrevistados consideram excelente utilizar essa ferramenta; $11 \%$ acham ótimo; $42 \%$, bom; $30 \%$, ruim; $14 \%$, regular. Considerando os parâmetros excelente, ótimo e bom como referência para uma boa aceitação da ferramenta, os resultados revelam que $56 \%$ gostaram da realização do chat, enquanto $44 \%$ não acharam uma experiência agradável.

Os dados sugerem que o chat representou um bom recurso pedagógico para elucidar as dúvidas em relação às questões trabalhadas nas listas de exercícios, pois promoveu maior interação entre o professor/tutor e os alunos e dos alunos entre si, validando assim a sua funcionalidade, conforme assinala Junqueira (2010), que foi a de promover a interação e a troca de conhecimentos.

Ademais, Gerosa et al (2003, p. 136) reforçam que "o uso contínuo e integrado das ferramentas de chat nas atividades educacionais constitui uma forma de manter os aprendizes motivados $e$ engajados para garantir o sucesso e a continuidade de cursos a distância". Portanto, as interações que ocorreram entre os componentes do curso foi uma oportunidade para expandir e aprimorar o conhecimento científico, algo muito difícil de obter individualmente.

Gráfico 3: Opinião sobre o chat - dado coletivo

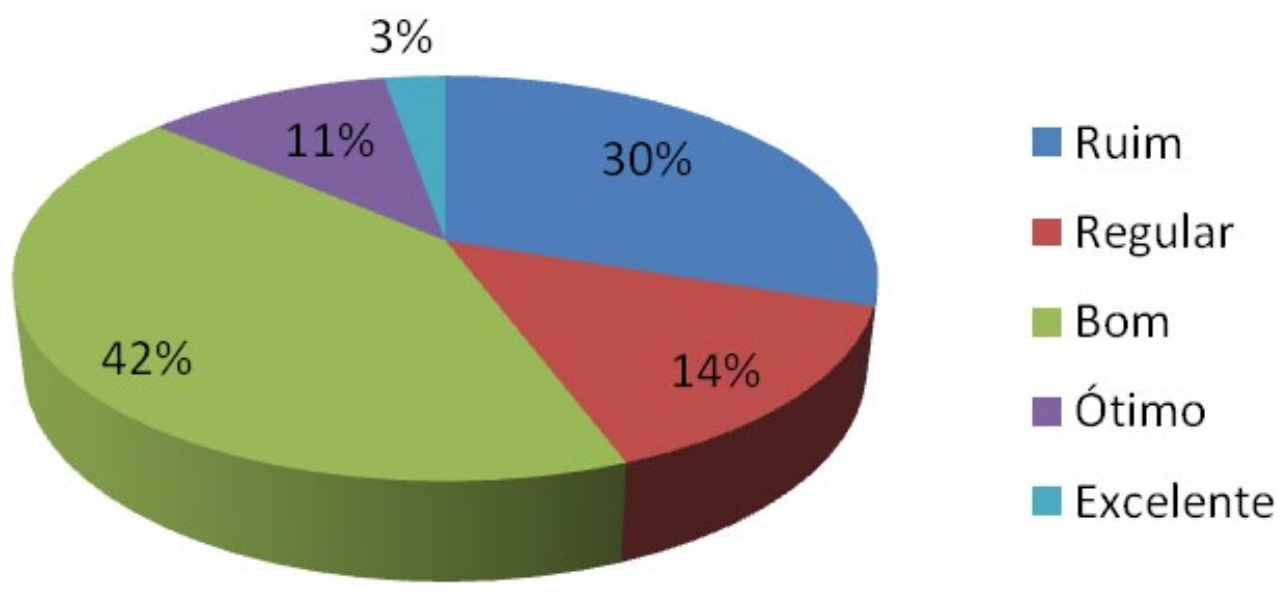

Fonte: Pesquisa direta 
Gráfico 4: Opinião sobre o chat - dado individual

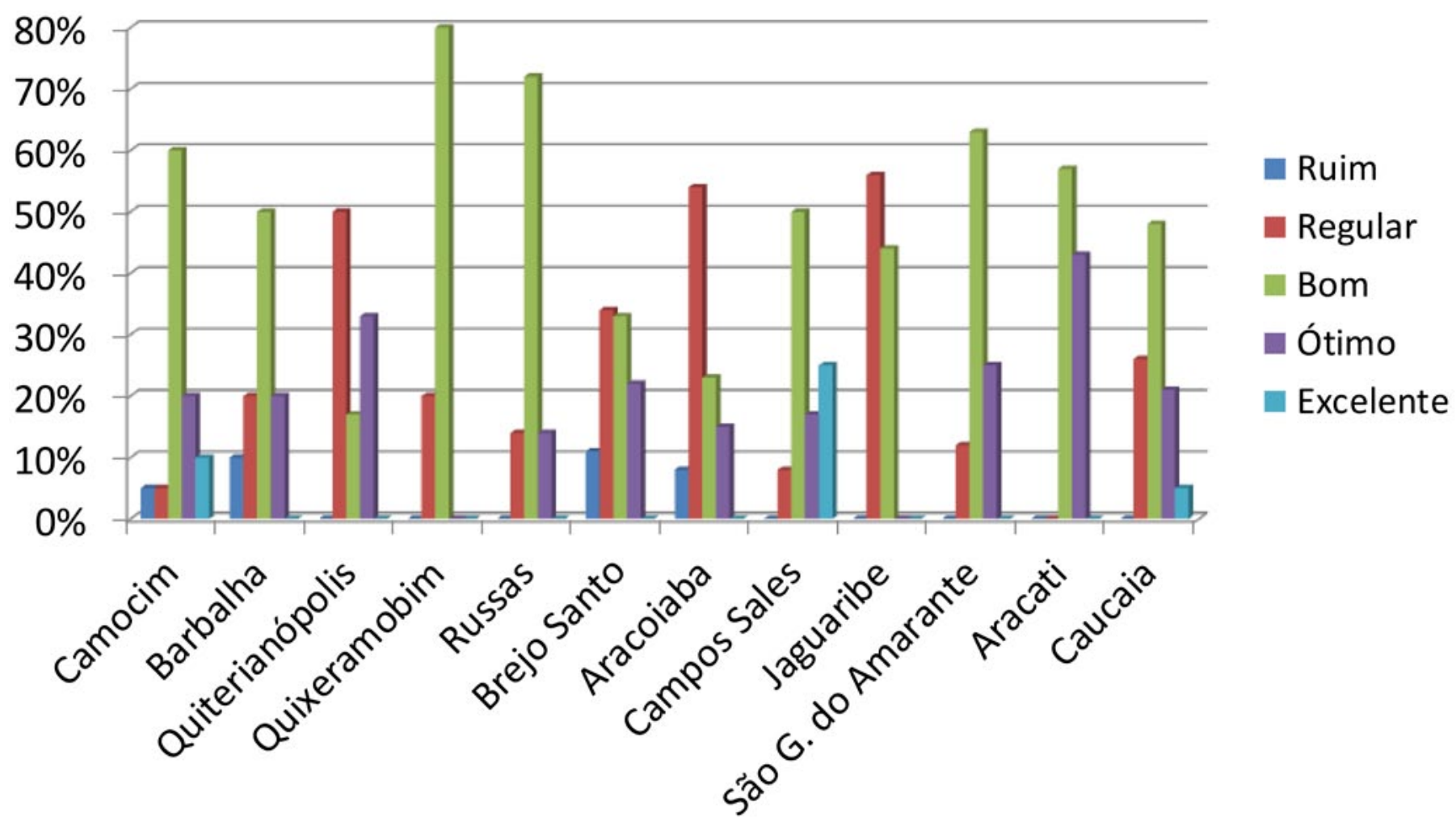

Fonte: Pesquisa Direta

Os dados apresentados no Gráfico 4 destacam que apenas em três polos: Quiterianópolis, Aracoiaba e Jaguaribe e acentuam que a utilização dessa ferramenta para resolução de exercícios é considerada regular, porém nos demais polos percebemos que o chat se constituiu em uma boa ferramenta, haja vista que os conceitos excelente, ótimo e bom estiveram presentes na avaliação dos demais polos. Com relação ao polo de Aracoiaba, é compreensivo que ele aponte como regular a opinião sobre o uso do chat, pois esse polo apresentou dificuldade de acesso a Internet durante a realização das duas disciplinas.

Mesmo com a limitação da internet nestes polos, argumentamos que a inserção do chat nas disciplinas foi importante, tendo em vista que possibilitou a diminuição da barreira geográfica entre professores/tutores e alunos, ampliou o espaço para a discussão e reflexão em grupo, diminuiu o tempo de resposta às questões e dúvidas dos alunos, possibilitou a incorporação de novas contribuições para a construção do conhecimento e provavelmente, de acordo com Perreira (2004), favoreceu a atenuação da desinibição por parte dos alunos, possibilitando maior liberdade de expressão.

\section{Questão 2: Dificuldades na utilização do chat}

O Gráfico 5 expôs que 35\% dos alunos apontam o conteúdo específico da Física; $26 \%$ destacaram o acúmulo de mensagens; $18 \%$ atribuem as dificuldades à navegação no ambiente Solar; $15 \%$, relacionam à falta de orientação do professor/tutor; e $6 \%$ indicam outras problemáticas, como por exemplo, falta de energia. 
Gráfico 5: Dificuldade no uso do chat - dado coletivo

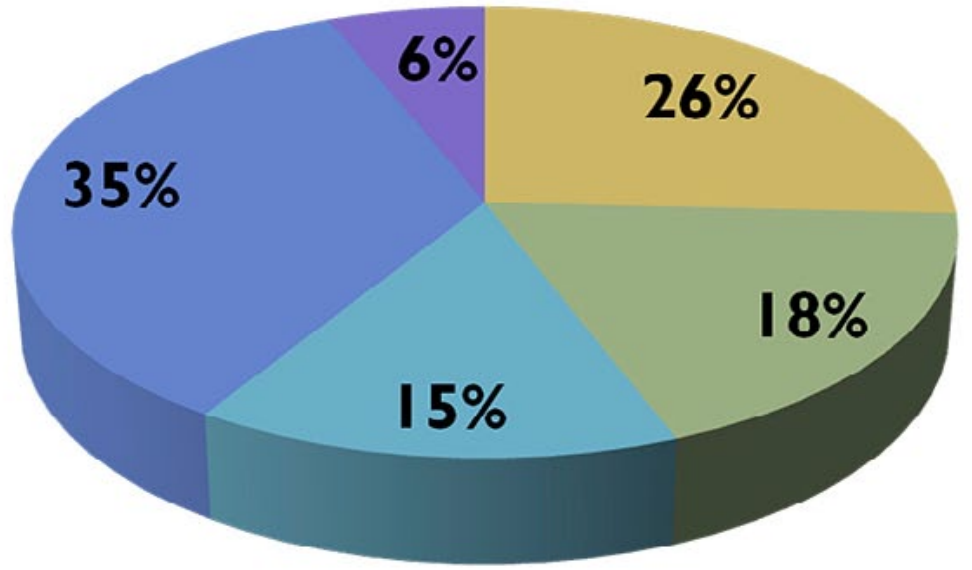

\section{Acúmulo de mensagens enviadas \\ Navegação no ambiente Chat}

Orientações do Tutor

O Conteúdo da Física

Outros

Fonte: Pesquisa Direta

Gráfico 6: Dificuldade no uso do chat - dado individual

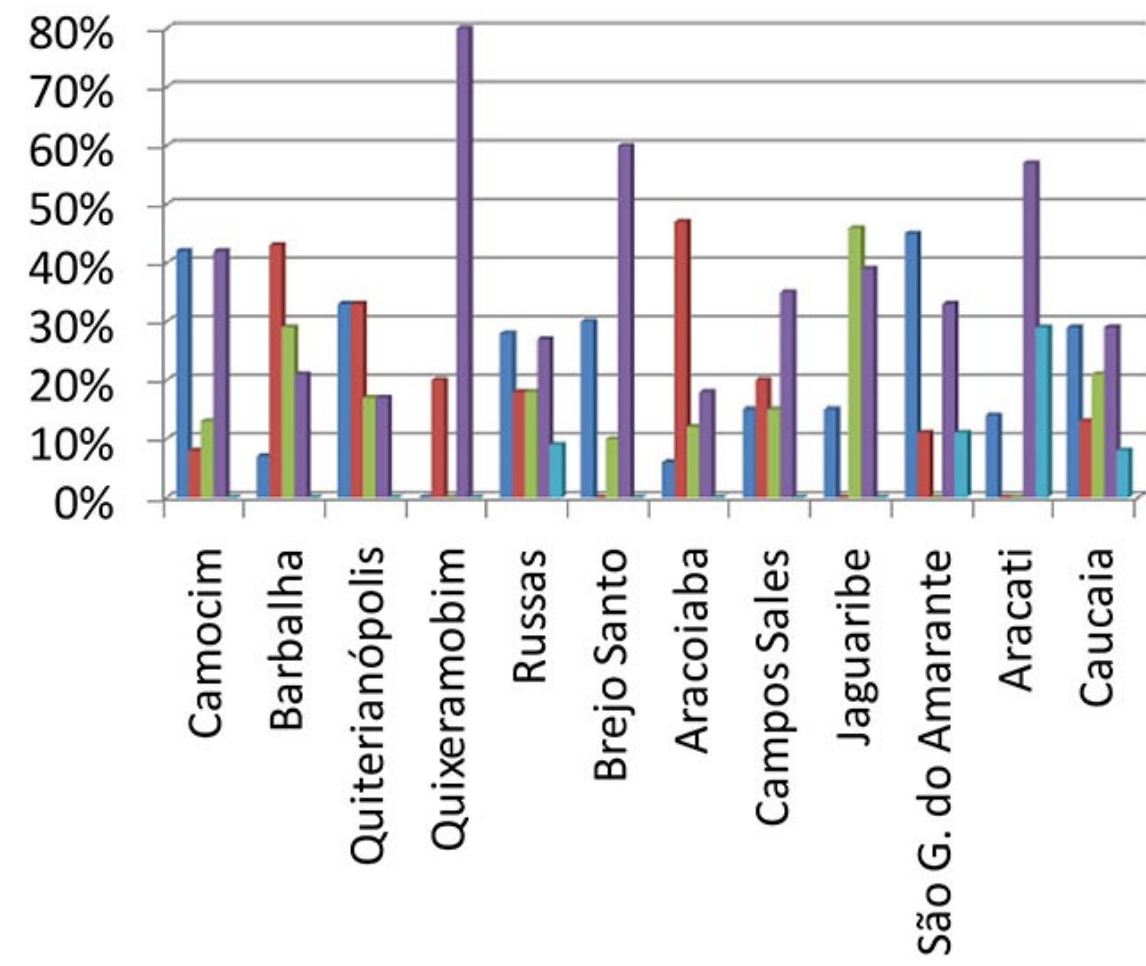

Acúmulo de mensagens enviadas

n Navegação no ambiente Chat

Orientações do Tutor

- O Conteúdo da Física

Fonte: Pesquisa Direta 
O Gráfico 6 mostra que os alunos dos polos de Quixeramobim, Brejo Santo e Aracati consideram como maior entrave o próprio conteúdo da Física, em contrapartida, os estudantes dos polos de Barbalha e Aracoiaba apontaram como dificuldade a navegação no ambiente chat; esse fato talvez possa ser explicado pela baixa qualidade da conectividade da internet nesses dois polos.

Os dados dos dois gráficos ressaltam que as maiores dificuldades com o uso do chat no ensino de Física são decorrentes do conteúdo específico dessa área em estudo, de várias mensagens que são enviadas ao ambiente ao mesmo tempo, prejudicando a leitura das mensagens e as dificuldades de navegação no contexto do chat. Esse dinamismo do chat legitima o pensamento de Junqueira (2010), quando comunica que as mensagens aparecem em um ritmo agitado e com uma movimentação que impossibilita a leitura de todas as mensagens.

\section{Questão 3: Sobre a dinâmica do chat no ensino de Física}

O Gráfico 7 evidencia que os percentuais das respostas dos alunos foram: $24 \%$ destacaram que os procedimentos didáticos do professor/tutor à distância favoreceram a aprendizagem; 30\%, que as questões comentadas nos chat foram viáveis $e$ contribuíram para a aprendizagem, $28 \%$ assinalam que os assuntos discutidos foram apropriados em relação às suas necessidades, $17 \%$ dos pesquisados ressaltaram que a relação interpessoal professor/tutor e aluno favoreceu a aprendizagem e $1 \%$ apontou o item outros.

Gráfico 7: Dinâmica do chat - dado coletivo

O conteúdo discutido foi apropriado em relação às suas necessidades

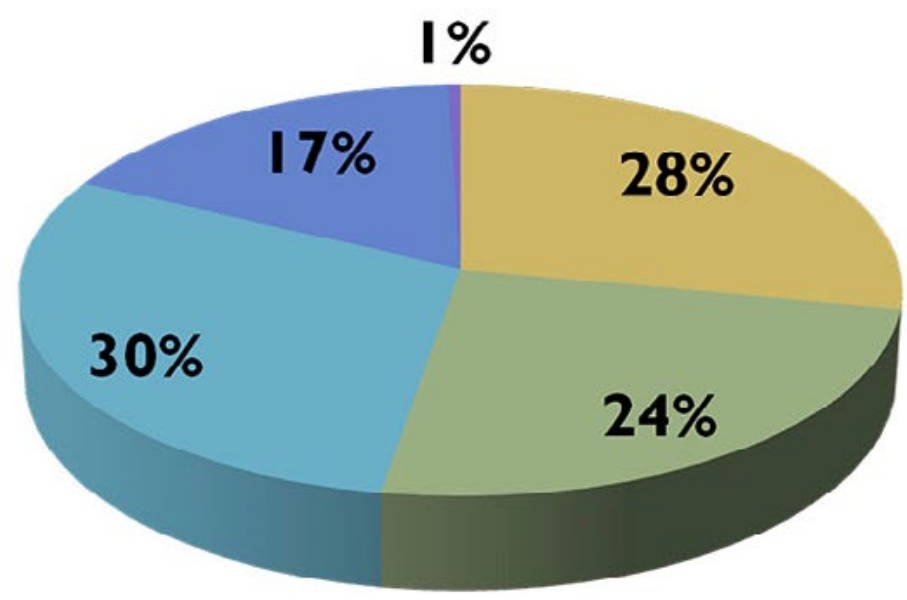

Os procedimentos didáticos do tutor a distância favoreceram a aprendizagem

As questões abordadas foram viáveis à aprendizagem

\section{A relação interpessoal tutor a distância /aluno favoreceu a aprendizagem \\ Outros}

Fonte: Pesquisa direta 
Gráfico 8: Dinâmica do chat - dado individual

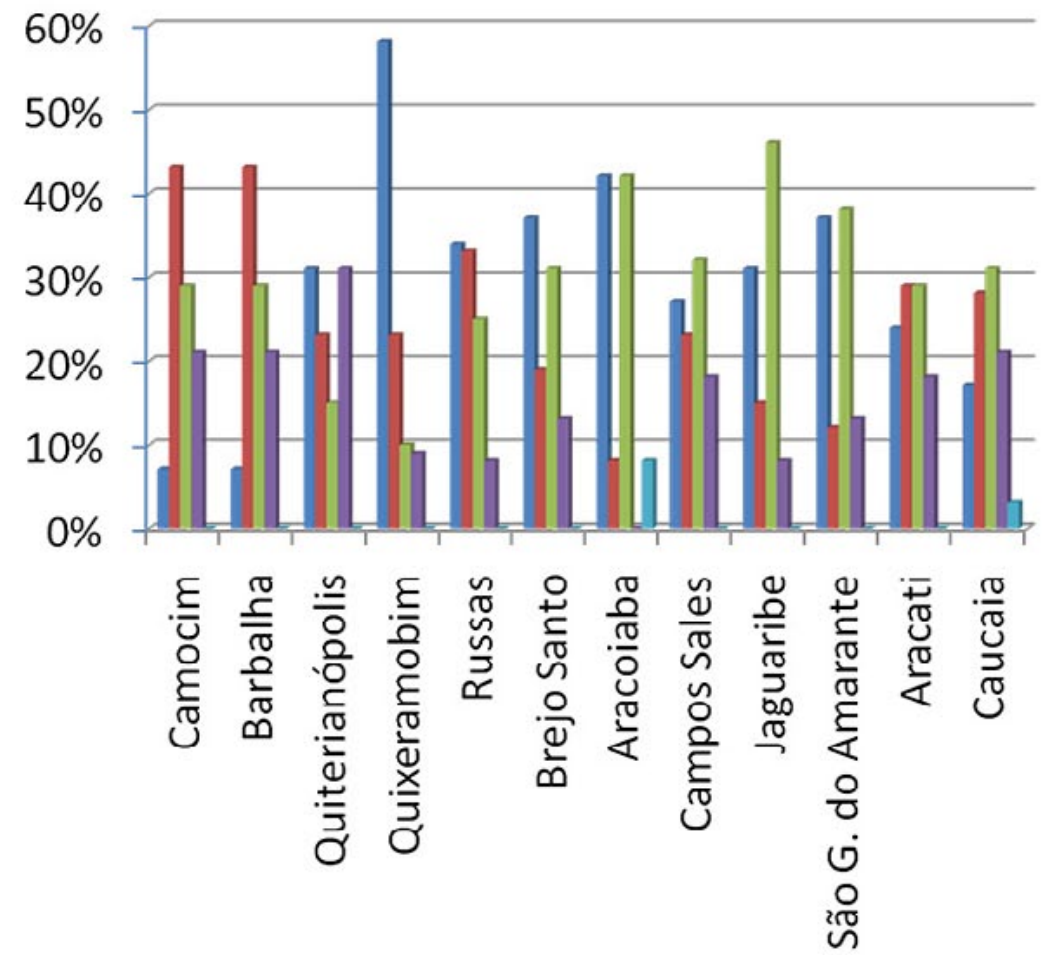

O conteúdo discutido foi apropriado em relação às suas necessidades

Os procedimentos didáticos do tutor a distância favoreceram a aprendizagem

As questões abordadas foram viáveis à aprendizagem

A relação interpessoal tutor a distância /aluno favoreceu a aprendizagem

Fonte: Pesquisa direta

O Gráfico 8 revela o polo de Quixeramobim como o que mais se destacou, apontando o item: o conteúdo discutido foi apropriado em relação às necessidades. Nos demais polos os resultados oscilaram entre os procedimentos didáticos do tutor à distância $e$ as questões discutidas no chat. Os dados de ambos os gráficos nos permitem afirmar que o trabalho do professor/tutor no que se refere à mediação entre o conteúdo e o aluno foi satisfatório, apesar das limitações do chat para a área de Física. O uso do chat possibilitou ainda corrigir erros conceituais em um período curto de tempo, decorrente da percepção imediata do professor/tutor da captação de problemas e compreensão dos conceitos abordados. Esse fato destaca o comentário de Almeida (2006), quando ele ilustra que o chat favorece a reorganização de conceitos.
A constituição do professor/tutor, de acordo com Pereira (2004), deve estar fundamentada em quatro características básicas: conhecimento em educação (didática, metodologia, planejamento de ensino e avaliação), domínio tecnológico (reconhecer a importância e operacionalizar o computador), especificidade de formação (domínio do conteúdo específico) e transposição didática (transformar o conhecimento científico em um conhecimento para a prática escolar). $\mathrm{O}$ trecho a seguir robustece esse fato, quando o professor busca se utilizar de uma linguagem matemática nada convencional para ajudar o aluno na compreensão dos conceitos.

Professor/tutor fala para TODOS:

antes de tudo precisamos calcular a aceleração do sistema:

Professor/tutor fala para TODOS:

para o corpo $B: V=v 0+a \cdot t$ 


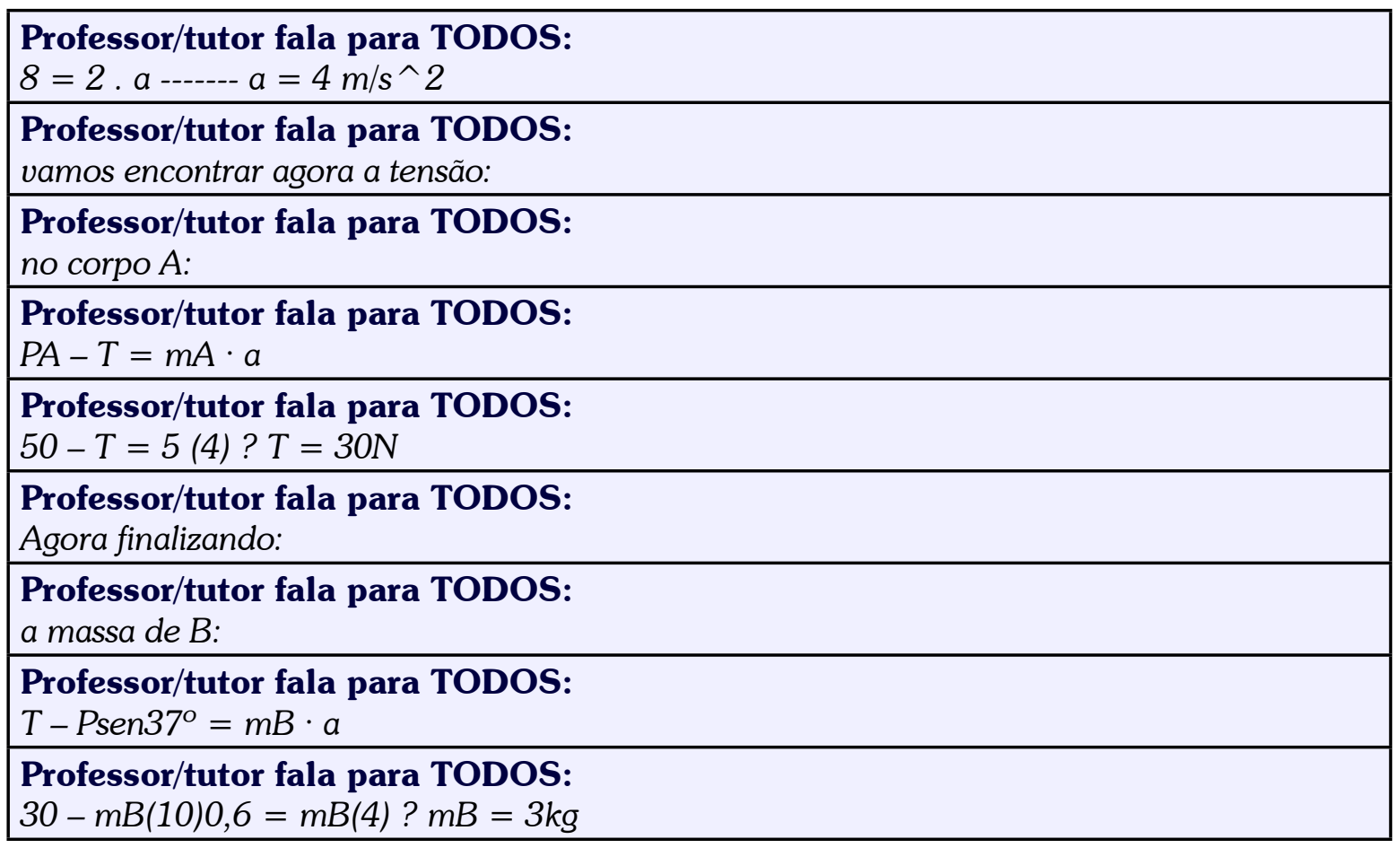

Fonte: Sessão de chat de Física Introdutória I, realizado no dia 2 de setembro de 2010.

Pelo trecho apresentado, percebemos a limitação que a ferramenta chat possui com relação à linguagem simbólica da Física, ou seja, os diálogos ficam prejudicados, pois as representações das equações, potências, cálculos e outros não são escritos de forma correta, limitando assim as expressões de conceitos de Física. Essas restrições corroboram as observações já feitas por Junqueira (2010) quando expressava que a interface do ambiente chat é predominantemente textual, não possibilitando a utilização de recursos gráficos e de fórmulas matemáticas tão necessárias às discussões dos conteúdos específicos da área das Ciências Exatas.

Para amenizar essas dificuldades, o autor recomenda que o professor/tutor envie antecipadamente aos alunos, por meio do ambiente virtual de aprendizagem, materiais diversos, como textos tradicionais, apostilas, figuras, equações, softwares e outros que poderão ser consultados durante o chat.

\section{Considerações finais}

No que concerne às contribuições da ferramenta chat para o ensino de Física, os dados permitem sugerir que, apesar de suas limitações, ele favorece o processo educacional quando é usado também para esclarecer dúvidas, pois promove maior interação entre o professor/tutor e os alunos e dos alunos entre si, validando assim a sua funcionalidade, que é promover interação e troca de conhecimentos, diminuindo assim a sensação de distância.

Este estudo também possibilitou que percebêssemos a riqueza da ferramenta chat para o processo de ensino e de aprendizagem. As interações que ocorreram permitiram que uma tarefa tão difícil como a resolução de lista de exercícios de Física em EaD fosse concretizada. A dificuldade maior detectada foi à ausência de um editor de fórmulas matemáticas no ambiente chat.

As características das mensagens analisadas nos chats permitem ressaltar ainda os benefícios da ferramenta, pois a permissividade que é dada aos alunos, de expor suas ideias e cooperar para a construção de conhecimento, contribuindo para o trabalho colaborativo entre todos os agentes envolvidos no chat. 


\section{Referências}

ALMEIDA, Maria Elizabeth B. Educação, ambientes virtuais e interatividade. In: SILVA, Marco (Org). Educação Online. São Paulo: Loyola, 2006, 210 p. p. 203-218.

BARDIN, Laurence. Análise de conteúdo. (L. de A. Rego \& A. Pinheiro, Trads.). Lisboa: Edições 70, 2008.

CHIZZOTTI, Antonio. Pesquisa em ciências humanas e sociais. 8a ed. São Paulo: Cortez, 2006.

DAVID, Priscila B. Interações contingentes em ambientes virtuais de aprendizagem. 2010. Tese (Doutorado em Educação), Faculdade de Educação, Universidade Federal do Ceará, 2010.

GEROSA, Marco et al. Coordenação de fóruns educacionais: encadeamento e categorização de mensagens. In: XIV Simpósio Brasileiro de Informática na Educação, 12. 2003, Rio de Janeiro. Anais... Rio de Janeiro: NCEIM/UFRJ, 2003, p. 1-10.

JUNQUEIRA, Eduardo S. O uso do chat em EaD: uma proposta metodológica. Disponível em $<$ http:// www.vdl.ufc.br/solar/aula_link/ffis/semestre01/EAD/aula_02-1231/02_arquivos/Aula_02_como_realizar_um_ chat_educativo.doc $>$. Acesso em 26 ago. 2010.

LEAL, Viviane P. L. V. O chat quando não é chato. O papel da mediação pedagógica em chats educacionais. In: ARAÚJO, Júlio C. (org.). Internet \& ensino: novos gêneros, outros desafios. Rio de Janeiro: Lucerna, 2007.

LINS, Rubevan M.; MOITA, Márcia H. V.; DACOL, Silvana. Interatividade na Educação a Distância. Fortaleza/CE: XXVI ENEGEP, 2006. Disponível em: <http://www.abepro.org.br/biblioteca/ENEGEP2006_ TR540364_8555.pdf >. Acesso em: 01 dez. 2010.

MAIA, Carmem; MATTAR, João. ABC da EaD - Educação a distância hoje. São Paulo: Pearson, 2007.

MARTINS, Janae. G.; OLIVEIRA, Jeane. C.; CASSOL, Marlei. P. Chat - Um recurso educativo para auxiliar na avaliação de aprendizagem baseada na web. 2005. Disponível em: <http//www.abed.org.br/ congresso2005/por/pdf/176tcc3.pdf > . Acesso em: 16 set. 2010.

PEREIRA, Viviane de O. Bate-papo na Internet: algumas perspectivas educativas. 2004. 190 p. Dissertação (Mestrado em Educação). Faculdade de Educação, Universidade Federal do Ceará, 2004.

PRATT, Keith; PALLOFF, Rena M. O aluno virtual: um guia para trabalhar com estudantes online. Porto Alegre: Artmed, 2004. 